\title{
Classical Versus Laparoscopic Approach in Retroperitoneal Lesions - Advantages and Limitations
}

\author{
Crăciun $C^{1}$, Azamfirei L2 , Coroș MF¹, Crăciun RC³ \\ 1 Surgical Clinic 1, County Clinical Hospital, Tîrgu Mureș, Romania \\ 2 ICU Clinic 1, County Emergency Clinical Hospital, Tîrgu Mureș, Romania \\ 3 "luliu Hațieganu" University of Medicine and Pharmacy, Cluj Napoca, Romania
}

Background: At present, the laparoscopic intervention in retroperitoneal primitive tumors, abscesses, haematomas and retroperitoneal effusions is still a challenge. The purpose of this paper is to identify the differences between laparoscopic and conventional surgical interventions in diseases of the retroperitoneum.

Material and method: The study follows a retrospective analysis of various retroperitoneal interventions performed on 62 patients between 2010-2012 in the Surgery Clinic 1 of Mures County Hospital. We have chosen from the casuistry the cases with tumoral diseases or nontumoral and divided the patients into two groups: group I who had undergone classic interventions and group II who had undergone laparoscopic procedures. We studied the clinical medical records, surgical protocols and anatomopathological results.

Results: For 2010 we extracted 23 cases (39,2\% classical interventions), for $2011-21$ patients (31,4\% classic) and for 2012 -18 cases (29,4\% classical interventions). According to the type of the disease, 30 classical interventions were performed for tumoral formations and 21 interventions for non-tumoral formations. Laparoscopic tumoral cases included three tumors and a retroperitoneal metastasis, while the non-tumoral were represented by 7 urohaematic effusions as a result of percutaneous nephrolithotomy procedures.

Conclusions: Laparoscopic surgery of retroperitoneal lesions is minimally invasive, the postoperative evolution of patients is favorable, without major complications.. Classical intervention of retroperitoneal lesions is indicated in large haematomas, abscesses, and big invasive tumors with vascular factor which does not allow the use of laparoscopic technique.

Keywords: retroperitoneum, laparoscopy, classical surgery

Received: 22 April 2013

\section{Introduction}

In medical practice the retroperitoneal space is perceived as an area lying behind the posterior peritoneal foil together with its pelvi-subperitoneal extension.

The retroperitoneum hosts various anatomical structures: vessels, nerves, muscles, sympathetic ganglia, lymph vessels and nodes, ectopic and glandular tissues and embryonic remnants which belong to this area and are surrounded by a fat and fibrous connective tissue of different thicknesses and density. All these elements of the retroperitoneal area have a vast pathology. The treatment of various diseases requires multidisciplinary teams in which surgical treatment is essential $[1,2]$.

Although the laparoscopic technique is less used in the surgical interventions of retroperitoneal lesions, in time, with the development of laparoscopic surgical devices and instruments and the emergence of experienced surgical teams in the field, it was possible for some retroperitoneal lesions to be operated using this technique. Adrenal gland surgery, nephrectomies and retroperitoneal lymphadenectomies are performed in some centers using routine surgical laparoscopic procedures.

Correspondence to: Călin Crăciun

E-mail: c.craciun.calin@gmail.com
At present, the laparoscopic intervention of retroperitoneal primitive tumors (RPT), abscesses, haematomas and retroperitoneal effusions is still a challenge. This is caused on one hand by the anatomic and clinical variety of these lesions, and on the other hand by their low incidence which leads to difficulty in achieving a study based on large samples which could establish the attitude in these situations.

The purpose of this paper is to identify the differences between laparoscopic versus conventional surgical interventions in diseases of the retroperitoneum.

\section{Material and method}

We carried out a retrospective analysis of various retroperitoneal interventions performed on 62 patients between 2010-2012 in the Surgical Clinic 1 of the County Clinical Hospital of Tîrgu Mureș.

We chose from the casuistry the cases with tumoral (primary tumors, metastases, cysts) or non-tumoral diseases (effusions, abscesses, haematomas) and divided the patients into two groups: group I had undergone classic interventions (51 patients) and group II (11 patients) who underwent an laparoscopic intervention.

We studied the clinical medical records, surgical protocols and histopathological results. Thus, the two groups were analyzed comparatively, following the demographic 
distribution, patient pathology, duration of surgery, number of days of hospitalization, duration of post operatory analgesia, evolution and immediate postoperative complications. We also had in view the patients' condition when discharged from the hospital, other reinterventions (if any) within that period and their causes as well.

Inclusion criteria: among patients with retroperitoneal tumors, we selected those who had primitive tumors (RPT), relapses after RPT surgery with complete excisions and metastases localized at this level. The selected patients with non-tumoral retroperitoneal diseases were those with suppurating lesions, effusions, haematomas, retroperitoneal fibrosis or malakoplaky.

Exclusion criteria: patients with retroperitoneal tumoral invasion of adjacent organs or patients with various types of renal tumors, of the adrenal glands and pancreas were not included in the study.

Statistical analysis was performed using MedCalc Software (Version 12.3.0, Mariakerke, Belgium). Student's t test was used to assess differences between the means of continuous variables (expressed as mean $\pm \mathrm{SD}$ ), while the $\chi^{2}$ test was used for categorical variables expressed as number (\%). Differences between nonparametric variables (expressed by median, range) were compared using the Mann-Whitney $U$ test. A p value $<0.05$ was considered to be statistically significant.

\section{Results}

\section{Clinical and demographic data of patients included in the study}

For 2010 we extracted 23 cases $(39.2 \%$ classical interventions), for $2011-21$ patients (31.4\% classical interventions) and for 2012 - 18 cases (29,4\% classical interventions).

Table II. Intra- and postoperative results classic versus laparoscopic interventions

\begin{tabular}{|c|c|c|c|c|}
\hline & \multirow[t]{2}{*}{ Variable } & Classic & Laparoscopic & \multirow[t]{2}{*}{$p$} \\
\hline & & $\begin{array}{c}\mathrm{n}=51 \\
(82.3 \%)\end{array}$ & $\begin{array}{c}n=11 \\
(17.7 \%)\end{array}$ & \\
\hline \multirow{3}{*}{$\begin{array}{l}\text { Type of anes- } \\
\text { thesia }\end{array}$} & IOT, no (\%) & $50(98.03 \%)$ & $11(100 \%)$ & 0.57 \\
\hline & Local,no(\%) & $0 \%$ & - & \\
\hline & Spinal, no (\%) & $1(2.0 \%)$ & - & \\
\hline $\begin{array}{l}\text { Duration of } \\
\text { intervention }\end{array}$ & min, median (range) ${ }^{*}$ & $80(10-240)$ & $80(35-180)$ & 0.8 \\
\hline $\begin{array}{l}\text { Days of } \\
\text { admission }\end{array}$ & days,median (range) ${ }^{\star}$ & $9(4-49)$ & $7(2-10)$ & 0.04 \\
\hline $\begin{array}{l}\text { ICU admission } \\
\text { days }\end{array}$ & days, median (range) ${ }^{\star}$ & $1.5(0-5)$ & $1(0-2)$ & 0.16 \\
\hline \multirow{3}{*}{$\begin{array}{l}\text { Postoperative } \\
\text { evolution }\end{array}$} & Favor, no (\%) & 39 (76.6\%) & $11(100 \%)$ & 0.17 \\
\hline & Complicated, no (\%) & $9(17.6 \%)$ & - & - \\
\hline & Bad, no (\%) & $3(5.8 \%)$ & - & - \\
\hline \multirow{4}{*}{$\begin{array}{l}\text { Discharge } \\
\text { status }\end{array}$} & Healed, no (\%) & 39 (76.6\%) & $11(100 \%)$ & 0.08 \\
\hline & Improved, no (\%) & $5(9.8 \%)$ & - & - \\
\hline & Stationary, no (\%) & $4(7.7 \%)$ & - & - \\
\hline & & $3(5.9 \%)$ & - & - \\
\hline
\end{tabular}

*Mann Whitney test
Table I. Demographic and clinical characteristics of the study subjects

\begin{tabular}{|c|c|c|c|c|}
\hline & \multirow[t]{2}{*}{ Variable } & Classic & Laparoscopic & \multirow[t]{2}{*}{$p$} \\
\hline & & $\begin{array}{c}\mathrm{n}=51 \\
(82.3 \%)\end{array}$ & $\begin{array}{c}n=11 \\
(17.7 \%)\end{array}$ & \\
\hline \multirow[t]{3}{*}{ Year } & 2010, no (\%) & $20(39.2 \%)$ & 3 (27.3\%) & 0.7 \\
\hline & 2011, no (\%) & 16 (31.4\%) & $5(45.4 \%)$ & 0.6 \\
\hline & 2012, no (\%) & 15 (29.4\%) & $3(27.3 \%)$ & 0.8 \\
\hline Age & $(m e a n \pm S D)^{*}$ & $56.2 \pm 11.7$ & $47.1 \pm 14.9$ & 0.02 \\
\hline \multirow[t]{2}{*}{ Gender } & Male, no (\%) & $20(39.2 \%)$ & $5(45.5 \%)$ & 0.9 \\
\hline & Female, no (\%) & $31(60.8 \%)$ & $6(54.5 \%)$ & \\
\hline \multirow{2}{*}{$\begin{array}{l}\text { Type of } \\
\text { intervention }\end{array}$} & Appointment, no (\%) & $37(72.5 \%)$ & $5(45.5 \%)$ & 0.01 \\
\hline & Emergency, no (\%) & $14(27.5 \%)$ & $6(54.5 \%)$ & \\
\hline \multirow[t]{2}{*}{ Type affection } & Non-tumor, no (\%) & $21(41.1 \%)$ & 7 (63.6\%) & 0.7 \\
\hline & Tumor, no (\%) & $30(58.8 \%)$ & $4(36.4 \%)$ & \\
\hline Tumor diameter & $\mathrm{mm}$, median (range) ${ }^{\star \star}$ & $12(5-50)$ & $6(5-8)$ & 0.002 \\
\hline
\end{tabular}

*Student test; ${ }^{\star \star}$ Mann Whitney test

Mean age of patients with classical interventions was significantly higher than that of patients with laparoscopic interventions $(\mathrm{p}=0.02)$.

Regarding the type of interventions, approximately $2 / 3$ was scheduled for classical surgery compared with less than half of the cases in which laparoscopy was performed $(\mathrm{p}=$ 0.01).

According to the type of the disease, 30 classical interventions were performed for tumoral formations (22 retroperitoneal tumors, 4 metastases and 4 cysts) and 21 interventions for non-tumoral formations (17 abscesses and 4 haematomas). Laparoscopic tumoral cases included three tumors and a retroperitoneal metastasis and the non-tumoral were represented by 7 urohaematic effusions present after percutaneous nephrolithotomy procedures.

The diameter of the tumoral formations removed by laparoscopy was significantly lower compared with that of tumors excised classically $(\mathrm{p}=0.002)$ (Table I).

All laparoscopic interventions were performed under anesthesia by oro-tracheal intubation, this type of anesthesia applying to $98.03 \%$ of classical intervention. A patient with retroperitoneal tumor was operated by spinal anesthesia.

We have not found statistically significant differences in terms of intervention duration $(\mathrm{p}=0.8)$, the average being

Table III. Associated operations for retroperitoneal lesions in classic versus laparoscopic surgery

\begin{tabular}{lcccc}
\hline \multirow{2}{*}{ Operation } & \multicolumn{2}{c}{ Classic } & \multicolumn{2}{c}{ Laparoscopic } \\
\cline { 2 - 5 } & $\mathrm{n}=51(82.3 \%)$ & $\mathrm{n}=11(17.7 \%)$ \\
\hline Right hemicolectomy & 3 & $5.88 \%$ & 0 & $0 \%$ \\
Nephrectomy & 1 & $1.96 \%$ & 0 & $0 \%$ \\
Caudal splenopancreatectomy & 1 & $1.96 \%$ & 0 & $0 \%$ \\
Hysterectomy & 1 & $1.96 \%$ & 0 & $0 \%$ \\
Anexectomy & 2 & $3.92 \%$ & 0 & $0 \%$ \\
Subtotal gastrectomy & 1 & $1.96 \%$ & 0 & $0 \%$ \\
Cholecystectomy & 2 & $3.92 \%$ & 0 & $0 \%$ \\
Total & 11 & $21.56 \%$ & 0 & $0 \%$ \\
\hline
\end{tabular}


Table IV. Postoperative complications in interventions for retroperitoneal diseases laparoscopic versus classic interventions

\begin{tabular}{lcccc}
\hline \multirow{2}{*}{ Complication } & \multicolumn{2}{c}{ Classic } & \multicolumn{2}{c}{ Laparoscopic } \\
\cline { 2 - 5 } & $\mathrm{n}=51(82.3 \%)$ & $\mathrm{n}=11(17.7 \%)$ \\
\hline Retroperitoneal abscess & 2 & $3.92 \%$ & 0 & $0 \%$ \\
Retroperitoneal abscess with sepsis & 1 & $1.96 \%$ & 0 & $0 \%$ \\
Intestinal obstruction & 2 & $3.92 \%$ & 0 & $0 \%$ \\
Retroperitoneal hematoma & 1 & $1.96 \%$ & 0 & $0 \%$ \\
Acute pancreatitis & 1 & $1.96 \%$ & 0 & $0 \%$ \\
Wound pathology & 4 & $7.84 \%$ & 0 & $0 \%$ \\
Bronchopneumonia & 1 & $1.96 \%$ & 0 & $0 \%$ \\
Total & 12 & $23.52 \%$ & 0 & $0 \%$ \\
\hline
\end{tabular}

in both cases of 80 minutes. But the time spent in hospital was significantly reduced in patients who underwent laparoscopic interventions $(\mathrm{p}=0.04)$.

Approximately $53 \%$ of patients from the first group were hospitalized in the Intensive Care Unit for 1-5 days. In the second group $45.5 \%$ of the patients were admitted after intervention in the ICU for maximum 2 days.

The postoperative evolution was favorable in $76.6 \%$ of patients with classic interventions. All the patients who had laparoscopic surgery had a favorable evolution without complications.

There were 3 deaths from traditional interventions. There was no death in case of laparoscopic interventions, patients were discharged "surgically cured" (Table II).

Among patients operated for several retroperitoneal lesions by classical procedure, especially for tumors, 11 $(21.56 \%)$ underwent other concomitant interventions required by radical extirpation. Patients with laparoscopic surgery had no associated interventions (Table III).

There were 12 postoperative complications $(23.52 \%)$ in patients with classic surgery (Table IV).

In 11 patients $(21.56 \%)$ of those with classic surgery, reinterventions were needed, while in the second group, who had laparoscopic interventions, there were no reinterventions (Table V).
Table V. Postoperative reinterventions

\begin{tabular}{lcccc}
\hline \multirow{2}{*}{ Reintervention } & \multicolumn{2}{c}{ Classic } & \multicolumn{2}{c}{ Laparoscopic } \\
\cline { 2 - 5 } & $\mathrm{n}=51(82.3 \%)$ & $\mathrm{n}=11(17.7 \%)$ \\
\hline Incisions for evacuation with drainage & 4 & $7.84 \%$ & 0 & $0 \%$ \\
Hemostasis, laparotomy drainage & 1 & $1.96 \%$ & 0 & $0 \%$ \\
Release adhesions & 2 & $3.92 \%$ & 0 & $0 \%$ \\
Revision of plague & 4 & $7.84 \%$ & 0 & $0 \%$ \\
Total & 11 & $21.56 \%$ & 0 & $0 \%$ \\
\hline
\end{tabular}

\section{Discussions}

Today it is considered that the treatment of retroperitoneal lesions is multidisciplinary, and surgery is the main factor [1]. Most laparoscopic surgeries performed by us for non-tumoral retroperitoneal lesions were for urohaematic effusions, the result of percutaneous nephrolithotomy (PCNL). Patients operated by means of laparoscopy for urohaemoperitoneum post-PCNL were routinely monitored in the Intensive Care Unit for 24 hours. This may explain why in our study there was no statistically significant difference between the average days of hospitalization in the Intensive Care Unit between patients with classic or laparoscopic operation of retroperitoneal lesions.

For large post-traumatic retroperitoneal haematomas, with or without other organ damage but affecting the patient's hemodynamic evolution, we do not recommend laparoscopic surgery. Frequently, the source of bleeding is unknown and the haemostasis is difficult to be performed by laparoscopy.

Laparoscopic interventions of retroperitoneal abscesses and phlegmons are controversial. If they are not accessible to a process of eco- or CT-guided puncture-drainage, laparoscopic intervention is better to be done retroperitoneoscopically (in direct way) and not transperitoneally. The current intervention of retroperitoneal tumors is transperitoneal by a large, usually median laparotomy, which can be extended in any direction according to the situation found while operating [2].

Laparoscopic surgery of retroperitoneal tumors is in an exploration phase, and the literature publishes mostly

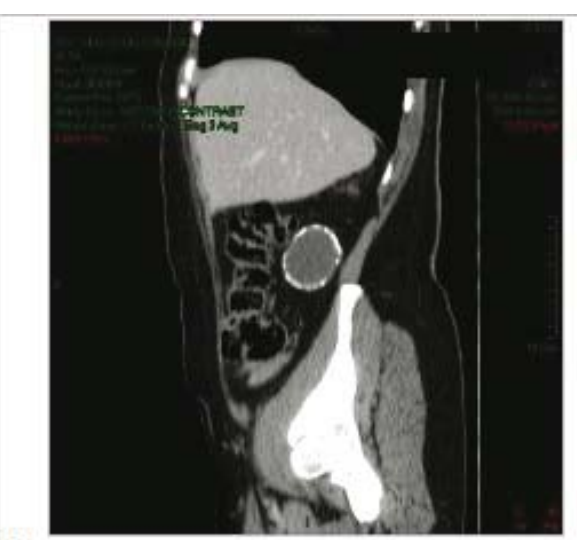

A

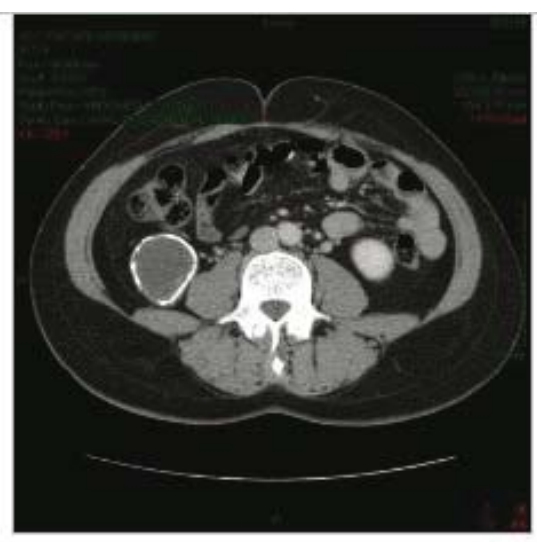

B

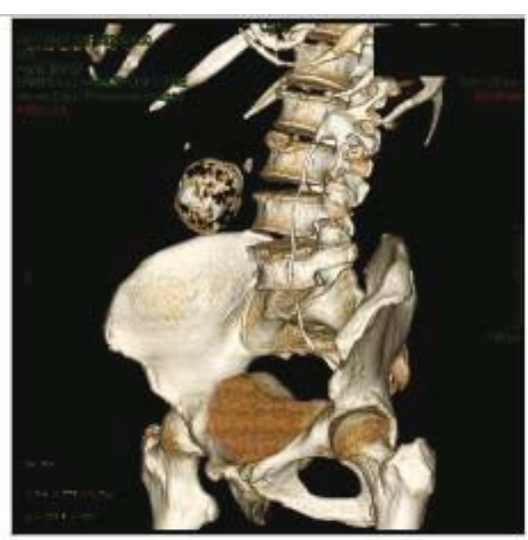

C

Fig. 1. Well defined retroperitoneal tumor of $6 \mathrm{~cm}$ in diameter located in the iliac lumbar region, operated laparoscopically. Myositis ossificans. CT aspect. A. sagittal view, B. transverse view, C. reconstruction. 


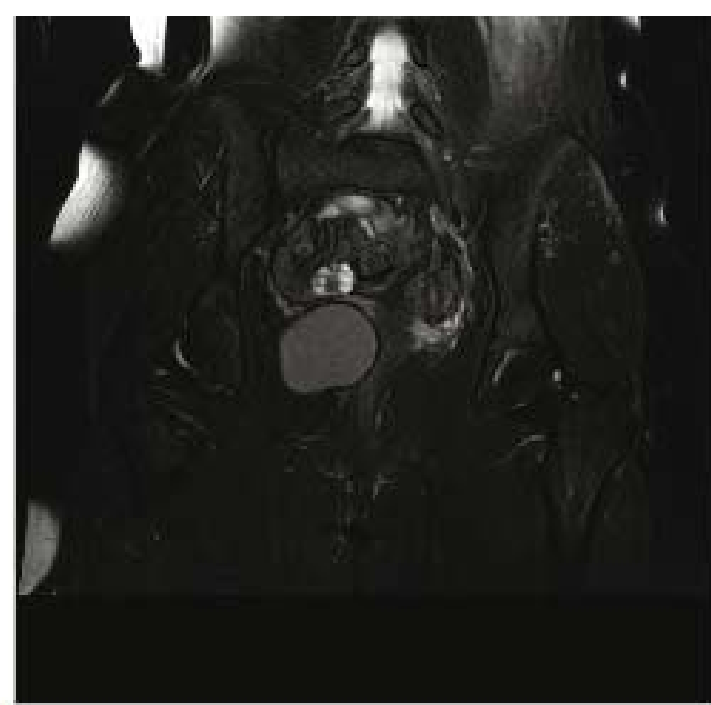

A

Fig. 2. Well defined retroperitoneal tumor with a diameter of $9 \mathrm{~cm}$ located in the subperitoneal pelvic region, operated laparoscopically. Teratoma. MRI aspects. A. frontal view, B. sagittal view.

individual cases, experiences are under evaluation. There are some situations dependent on anatomical, clinical and technical conditions when laparoscopic procedures can be used for retroperitoneal tumors.

Tumor size, tumor position, the anatomical relationship of the tumor with neighboring organs, as well as the vascular factor are also decisive in choosing the surgical procedure. Most times the vascular factor is the criterion that makes the laparoscopic procedure for removal of retroperitoneal tumors possible or not $[1,4]$. The position of the patient during the operation is also crucial for the success of laparoscopic surgery [5].

We foresee that the implementation of robotic laparoscopic intervention and three-dimensional visualization can overcome the difficulties regarding visualization, haemostasis and access to difficult areas of the retroperitone-

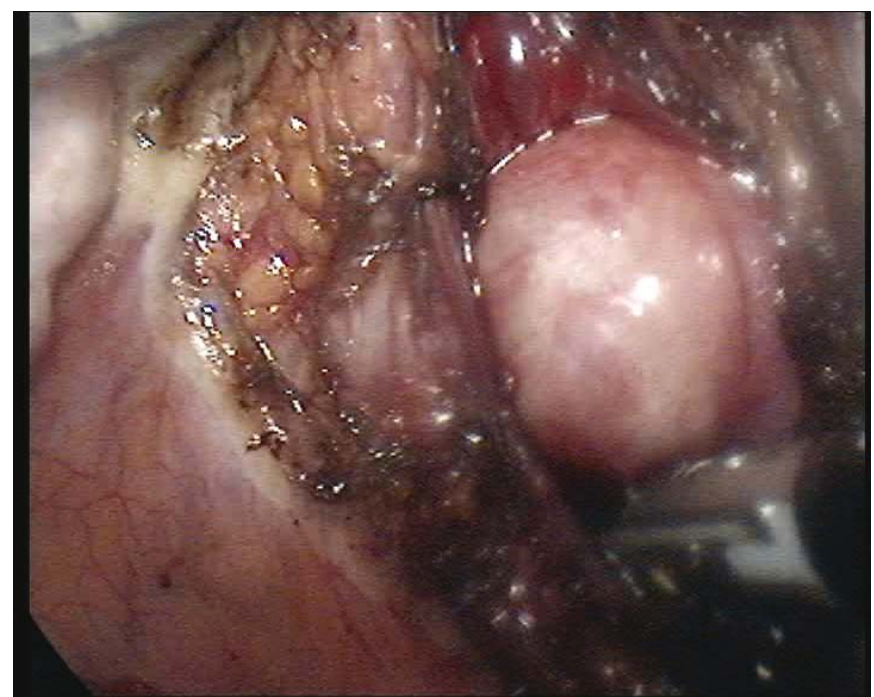

Fig. 3. Retroperitoneal tumor located within the pelvisubperitoneal space. Laparoscopic intraoperative aspect. um, issues which are encountered in case of robotic unassisted laparoscopic surgery. [ 6]

Of all retroperitoneal tumors we believe that lipomas are best suited to laparoscopic surgery, as they are easier to be handled, their dissection by laparoscopic procedure is easy, and their removal can be done in fragments without the risk of contaminating neighboring organs or abdominal wall.

The choice between classical or laparoscopic surgery for retroperitoneal lipomas is given by preoperative differential diagnosis between lipoma and liposarcoma. For a correct decision CT and MRI examination of these tumors is mandatory $[7,8,9]$. Although the information obtained by ultrasound examination, CT and MRI are very useful for obtaining a sure preoperative diagnosis, in case of retroperitoneal tumors, an ultrasound guided biopsy is needed.

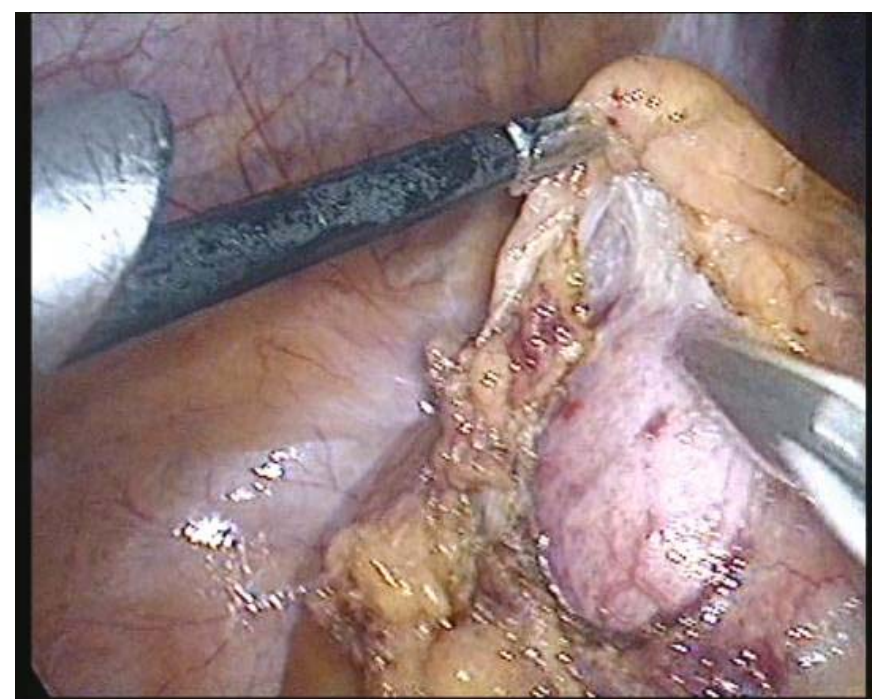

Fig. 4. Retroperitoneal tumor located in the iliac lumbar region. Laparoscopic intraoperative aspect. 
The difference between the average length of time between classic and laparoscopic surgery is not statistically significant in our study, fact which differs from the results obtained by other authors. This may be explained by the fact that many of the laparoscopic interventions carried out by us were for urohaemoperitoneum in emergency and they did not last more than 30-40 minutes. If we follow the cases, laparoscopic operations of retroperitonean tumors lasted 100-180 minutes, above the average time of conventional operations $[10,11]$.

The relatively high number of complications (12) and reinterventions (11) in patients undergoing classic surgery for retroperitoneal lesions compared with no complication or reintervention in patients with laparoscopic surgery may have two explanations. The first is related to the complexity of traditional interventions with associated operations, compared with laparoscopic interventions, and the second is related to the small number of cases with retroperitoneal lesions operated by means of laparoscopic surgery in the same period. This does not allow a very accurate conclusion regarding complications and postoperative evolution in classical interventions versus laparoscopic ones.

Difficulty of obtaining big sample of cases due to the low incidence of retroperitoneal lesions is a limit of this study in the analysis of major postoperative complications. This problem is reported by all authors, and the general conclusion is that the postoperative evolution is definitely better in patients operated on by means of laparoscopy.

\section{Conclusions}

Laparoscopic surgery of retroperitoneal lesions is minimally invasive. Even if the duration of interventions for RPT operated by means of laparoscopy is longer, the postoperative evolution of patients is favorable, without major complications to affect the general condition of the patient.
Pathology of plague is missing and the time of hospitalization is remarkably shorter than in patients with traditional interventions.

When tumor anatomy is well defined, without anatomic relationships with the large retroperitoneal vessels and size is acceptable, attempted laparoscopic transperitoneal removal is feasible and preferable.

Classical intervention of retroperitoneal lesions is indicated in large haematomas, abscesses, and big invasive tumors with vascular factor which does not allow the use of laparoscopic technique.

\section{References}

1. Popovici A. Patologia chirurgicală a spațiului retroperitoneal. In : Angelescu N, sub redacția. Tratat de Patologie Chirurgicală Vol II. București: Editura Medicală. 2001;1799-1824.

2. Vasile I, Vîlcea D, Nemes R, et al. Tumorile retroperitoneale primitive probleme de diagnostic si tratament. Chirurgia. 2005;100(1):27-33.

3. Young HC, Dae HK, Si HL et al. Laparoscopic Resection of a $12 \mathrm{~cm}$ Sized Retroperitoneal Schwannoma Adjacent to Retroperitoneal Vital Vessels: Are Large Retroperitoneal Schwannomas Not Suitable for the Laparoscopic Approach? J Korean Surg Soc. 2010;78(2):253-257.

4. Lazar AM, Brătucu E, Straja ND, et al. Primitive retroperitoneal tumors. Vascular involvement - a major prognostic factor. Chirurgia. 2012;107(2): 186-194.

5. Păun S, Gănescu R, Negoi I, Neștianu A. Abordul laparoscopic al tumorilor retroperitoneale primitive. Medical Connections. 2011;6(3):109-113.

6. Beuran M, Păun S, lordache F, et al. Chirurgia robotică - experiența inițială a Spitalului Clinic de Urgență București. In: Beuran M, Grigorescu M. Actualități medico-chirurgicale în patologia digestivă. Editura Medicală Universitară luliu Hațieganu, Cluj-Napoca. 2010;661-674.

7. van der Byl G, Cerica A, Sala MG. Retroperitoneal lipomas: A case report. Journal of Ultrasound. 2012;15(4):257-259.

8. Kransdorf MJ, Bancroft LW, Peterson JJ, Murphey MD,Foster WC, Temple HT. Imaging of fatty tumors: distinction of lipoma and well-differentiated liposarcoma. Radiology. 2002;224(1):99-104.

9. Sato M, Ishida H, Konno K, et al. Mesenteric lipoma: report of a case with emphasis on US findings. Eur Radiol. 2002;12(4):793-5.

10. Johna S, Shalita T, Johnson W. Laparoscopic-assisted resection of a large retroperitoneal tumor. JSLS.2004;8(3):287-89.

11. Shalhav AL, Chan SW, Bercowsky E, Elbahnassy AM,McDougall EM, Clayman RV. Laparoscopic exploration in the management of retroperitoneal masses. JSLS. 1999;3(3):209-14. 